\title{
Anorexia nervosa presenting as diffuse spontaneous air leaks
}

\author{
Timothy Shao Ern Tan, ${ }^{01,2}$ Janice Ser Huey Tan ${ }^{1,2}$
}

'Manchester Medical School, The University of Manchester, Manchester, UK

${ }^{2}$ Department of Diagnostic Radiology, Singapore General Hospital, Singapore

\section{Correspondence to} Dr Timothy Shao Ern Tan, timothy.tan.shao.ern@doctors. org.uk

Accepted 11 January 2019

\section{DESCRIPTION}

A previously well 23-year-old woman presented with a 4-month history of rapid weight loss of $15 \mathrm{~kg}$, increased lethargy, poor appetite and generalised chest and neck discomfort. Physical examination revealed generalised cachexia, bilateral temporalis muscle wasting and subcutaneous crepitus over the supraclavicular regions. Her body mass index (BMI) was low at $14 \mathrm{~kg} / \mathrm{m}^{2}$.

Chest radiograph (figure 1) revealed a small pneumomediastinum, left-sided hydropneumothorax, pneumoperitoneum and subcutaneous emphysema over the neck and upper chest walls. In addition, there was suggestion of free retroperitoneal air in the left hypochondrium. Further evaluation with CT (figure 2) confirmed the earlier radiographic findings and also demonstrated extension of the pneumomediastinum into the thoracic intraspinal epidural space (pneumorrhachis). Right lung apical subpleural blebs and a small left apical cystic lesion with surrounding ground-glass opacities possibly representing an infected bulla, were also noted. A water-soluble contrast swallow study performed showed no oesophageal or gastric perforation. Subsequent psychiatric evaluation revealed

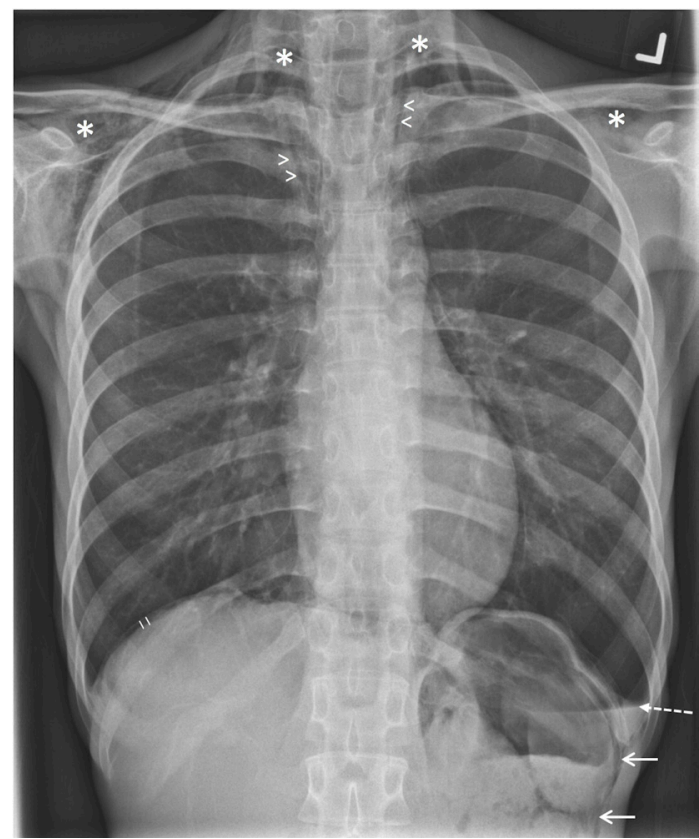

Figure 1 Erect chest radiograph demonstrating a left-sided hydropneumothorax (dashed arrow, with air-fluid level seen), pneumomediastinum (arrowheads), subcutaneous emphysema (asterisk), pneumoperitoneum (short lines) and suggestion of pneumoretroperitoneum (solid arrow). No gross pulmonary lesion was evident.

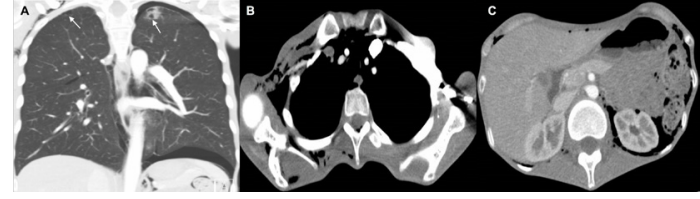

Figure 2 CT of the chest demonstrating additional findings of (A) a left apical bulla and right apical bleb (arrows), (B) pneumorrhachis and confirming the presence of $(C)$ pneumoretroperitoneum.

a diagnosis of restrictive subtype anorexia nervosa (AN). As the patient was relatively asymptomatic and no causative pulmonary disease was identified, she was conservatively managed with supportive care. The air leaks gradually resolved on subsequent chest radiographs. At the last follow-up, the patient remained clinically well with no recurrence and also showed improvement in her BMI.

Spontaneous non-traumatic air leaks outside the airways (ie, pneumothorax, pneumomediastinum, etc) occurring in isolation or in combination, are very rare. In the context of $\mathrm{AN}$, malnourishment has been closely linked to reduced lung surfactant production and emphysematous-like changes which increases susceptibility to tissue injury and poor

Learning points

- Spontaneous air leak syndromes such as pneumothorax and pneumomediastinum are rare, but life-threatening complications of anorexia nervosa (AN) that may also arise from emphysematous-like lung changes related to malnourishment. These should be considered in patients with AN presenting with respiratory symptoms.

- Prompt imaging with radiography, CT and fluoroscopy (where clinically indicated) should be performed to exclude any serious causes of diffuse air leaks such as a perforated viscus, which may require urgent surgical intervention. $\mathrm{CT}$ of the chest is useful in determining the extent of the air leaks as well as differentiating between their primary and secondary causes. $\mathrm{CT}$ is also essential in assessing for other pulmonary complications such as aspiration pneumonitis, mediastinitis and persistent alveolar-pleural fistula that can develop in severe cases of AN over time.

- The management approach of AN-associated air leaks is usually conservative until the source of the air leak resolves. 
healing. ${ }^{1} \mathrm{AN}$ is also associated with induced vomiting, which may cause oesophageal rupture and raised intrathoracic pressure, predisposing to developing pneumomediastinum, pneumothorax and pneumorrhachis. This is known as the Macklin effect, which postulates that alveolar rupture may result from increased intra-alveolar pressure and low perivascular pressure, causing air dissection through the thin alveolar walls and pulmonary interstitium into the mediastinum, pericardial, peritoneal cavities and less commonly, the epidural space, likely accounting for our patient's air leaks. ${ }^{2}$ This was further complicated by the formation of apical bleb/bulla likely secondary to her malnourished state, which may have ruptured into the interpleural space.

Other risk factors for developing spontaneous air leaks include male gender and vigorous exercise. ${ }^{2}$ The development of emphysematous-like lung changes without underlying pulmonary disease has also been reported in the HIV population, where bronchial dilation and premature bullous disease were seen in affected patients, predisposing to air leaks. ${ }^{3}$

When air leaks are identified, visceral organ injuries should be excluded as this would require surgical intervention. In severe cases of AN, a persistent alveolar-pleural fistula may develop and can be identified on CT. Depending on severity, the management of patients with AN-associated air leaks usually involves a medically conservative and multidisciplinary team approach until the source of the air leak heals. ${ }^{12}$ Currently, the duration required for restoration of normal pulmonary physiology and whether emphysematous-like changes will improve with refeeding are yet to be determined. ${ }^{1}$ However, patients generally recover well with spontaneous resolution of the air leaks without any significant sequelae.

Contributors TSET and JSHT were involved in conception and drafting of the article as well as performing the literature search. Both authors approved the final version.

Funding The authors have not declared a specific grant for this research from any funding agency in the public, commercial or not-for-profit sectors.

Competing interests None declared.

Patient consent Obtained.

Provenance and peer review Not commissioned; externally peer reviewed.

\section{REFERENCES}

1 Biffl WL, Narayanan V, Gaudiani JL, et al. The management of pneumothorax in patients with anorexia nervosa: a case report and review of the literature. Patient Safety in Surgery 2010;4:1.

2 Jensen VM, Støving RK, Andersen PE. Anorexia nervosa with massive pulmonary air leak and extraordinary propagation. Int J Eat Disord 2017;50:451-3.

3 Cook VJ, Coxson HO, Mason AG, et al. Bullae, bronchiectasis and nutritional emphysema in severe anorexia nervosa. Canadian Respiratory Journal 2001;8:361-5.

Copyright 2019 BMJ Publishing Group. All rights reserved. For permission to reuse any of this content visit https://www.bmj.com/company/products-services/rights-and-licensing/permissions/

BMJ Case Report Fellows may re-use this article for personal use and teaching without any further permission.

Become a Fellow of BMJ Case Reports today and you can:

- Submit as many cases as you like

- Enjoy fast sympathetic peer review and rapid publication of accepted articles

- Access all the published articles

- Re-use any of the published material for personal use and teaching without further permission

For information on Institutional Fellowships contact consortiasales@bmjgroup.com

Visit casereports.bmj.com for more articles like this and to become a Fellow 